\title{
MODELLING AND TORQUE TRACKING CONTROL OF PERMANENT MAGNET SYNCHRONOUS MOTOR FOR HYBRID ELECTRIC VEHICLES
}

\section{Mohd Sabirin Rahmat ${ }^{1}$, Fauzi Ahmad ${ }^{1 *}$, Ahmad Kamal Mat Yamin ${ }^{1}$, Vimal Rau Aparow $^{1}$ and Noreffendy Tamaldin ${ }^{1}$}

\author{
Smart Material and Automotive Control (SMAC) Group \\ Autotronic Laboratory, Faculty of Mechanical Engineering \\ UniversitiTeknikal Malaysia Melaka (UTeM) \\ Hang TuahJaya, Ayer Keroh 76100Durian Tunggal, Melaka, Malaysia \\ Phone: +6062346891; Fax: +6062346884 \\ E-mail: fauzi.ahmad@utem.edu.my
}

\begin{abstract}
This paper presents a detailed derivation of a permanent magnet synchronous motor, which may be used as the electric power train for the simulation of a hybrid electric vehicle. A torque tracking control of the permanent magnet synchronous motor is developed by using an adaptive proportional-integral-derivative controller. Several tests such as step function, saw tooth function, sine wave function and square wave function were used in order to examine the performance of the proposed control structure. The effectiveness of the proposed controller was verified and compared with the same system under a PID controller and the desired control. The result of the observations shows that the proposed control structure proves to be effective in tracking the desired torque with a good response. The findings of this study will be considered in the design, optimisation and experimentation of series hybrid electric vehicle.
\end{abstract}

Keyword: Modelling; permanent magnet synchronous motor; torque tracking control; Adaptive PID; PID controller.

\section{INTRODUCTION}

Vehicle purchases are important economic decisions for individual consumers and have important consequences for nations as a whole. Consumers can be expected to take both capital and operating costs into account when making their purchase decisions. Vehicles are typically the second most expensive purchase made by households, and the technology embodied in each vehicle determines its operating costs over its life. The major operating cost for vehicles is tied to consumer expenditure on gasoline, which is determined by the vehicle's fuel efficiency, daily miles driven and the price of gasoline. Petroleum prices were extremely volatile during the second half of 2008, with a per barrel price of West Texas Intermediate peaking at $\$ 133.37$ in July followed by a decline to $\$ 41.12$ by December; these prices translated to a national average per gallon price of regular gasoline of $\$ 4.06$ in July and $\$ 1.69$ by December (Yuan et al., 2004; Zhu et al., 2002). The extraordinary volatility in the cost of gasoline over the past few years has raised the level of uncertainty among consumers about future prices, and caused them to place greater weight on the expected variability and mean level of gasoline prices in their vehicle purchase decisions.

Concerns over the future prices of petroleum products have been accompanied by rising worries over both the impact of global warming due to carbon dioxide 
emissions and the nation's energy independence. The transportation sector accounted for one-third of all greenhouse gas emissions in the US in 2006. There are several federal programs designed to lower these emissions by requiring more fuel-efficient vehicles, including the recently enacted increase in the required corporate average fuel economy (CAFE) standards (Trigui et al., 2004). Concerns about potential disruptions to the oil supply and the resultant spike in gas prices, hybrid vehicles are chosen as a problem solver. This is because hybrid electric vehicles are a one of the most promising technologies for significantly reducing fuel consumption, and toxic and greenhouse gas emissions (Grammatico et al., 2010; Yimin et al., 2006). Generally, hybrid electric vehicles (HEV) can be defined as integrating an internal combustion engine (ICE) with an electric motor that is used as the prime mover of a vehicle. It can be classified into three commonly used categories: series HEV (Ehsani et al., 2010), parallel HEV (Momoh and Omoigui, 2009) and series-parallel HEV (Arroyo, 2006). In a series HEV system, the ICE is coupled with an electric generator that acts as the electric power supply to an electric motor instead of driving the wheels. While, the electric motor is employed as the prime mover in driving the vehicle wheels (Choi et al., 2006). Otherwise, a parallel HEV system is a combination of an ICE and electric motor where both power generators are used to drive the vehicle transmission and wheels. However, in a series-parallel HEV system, the mechanical and electrical systems are connected in double connection between the engine and drive axle. In this system, the split power path is able to interconnect the mechanical and electrical power structures. Planetary gear is applied in this system to make a connection between the mechanical and electrical devices (Bayindir et al., 2011; Pennestrì et al., 2012).

Since the electric motor is one of the important components in the HEV, the selection of electric motor type is seen to be compulsory. From past research, there are generally three types of electric motor commonly used in electric vehicles (EV) and HEVs, the induction motor, permanent magnet synchronous motor (PMSM) and switch reluctance motor (SRM). The three types of electric motor drive used depends on the type or specification desired to drive the vehicle. The PM synchronous servo motor drive plays a vitally important role in motion-control applications in the low-to-medium power range. The desirable features of the PM synchronous motor are its compact structure, high air gap flux density, high power density, high torque-to-inertia ratio, and high torque capability. Moreover, compared with an induction servo motor, a PMSM has advantages such as a higher efficiency, due to the absence of rotor losses and lower no-load current below the rated speed, and its decoupling control performance is much less sensitive to parametric variations in the motor (Desai and Williamson, 2009; Lin et al., 1998)

However the control performance of the PMSM drive is still influenced by the uncertainties of the controlled plant, which usually comprise of unpredictable plant parametric variationd, external load disturbances, and un-modelled and nonlinear dynamics. During the past few decades, the control of PMSM has resulted in various control strategies being developed. Numerous control methods such as adaptive control; neural control; and Fuzzy logic control, a nonlinear control strategy, has been applied to the control of PMSM by Bathaee et al. (2005), Guo et al. (2011) and Salmasi (2007), sliding mode control (SMC) by Guo et al. (2011) and Montazeri-Gh et al. (2006), terminal sliding mode control (TSM) by Qi and Shi (in press), and adaptive back stepping control by Li et al. (2009), Qi and Shi (in press) and Trabelsi et al. (2012). The Genetic Algorithm (GA) is proposed by Belda and Vosmik (2012) and Garg and Kumar (2002), and other intelligent control strategies have been proposed such as genetic fuzzy 
system (GFS) control (Karabacak and Eskikurt, 2011) and neuro fuzzy logic control (Elmas et al., 2008; Melin and Castillo, 2005; Moustakidis et al., 2008; Qi and Shi, in press). Among these, the best known is the proportional integral derivative (PID) controller, which has been widely used in the industry because of its simple structure and robust performance within a wide range of operating conditions (Ahmad et al., 2010; Astolfi et al., 2008; Cominos and Null, 2002; Huang et al., 2002; Kristiansson and Lennartson, 2002).

In this study, PMSM is chosen as the electric power train because of the superior performance of the motor, which can give a higher torque to inertia ratio compared to the others. The formulation and dynamic behaviour of a PM synchronous motor coupled with a complex mechanical system is introduced. MATLAB-Simulink software is chosen as the computer simulation tool used to simulate the system's behaviour and evaluate the performance of the control structure. Adaptive PID control is then proposed in controlling the output torque. The reason why adaptive PID control used in this study is because of the various throttle input values that will be applied to the vehicle, and because of the linearity in the limitation of the conventional PID controller where conventional PID control only can outperform in a predetermined range input reference only. The other reason for using this proposed control structure is because it is easy to maintain and easy to implement in the DAQ software during the experiment. The proposed controller structure will is then be used in the real experimentation of the $\mathrm{HEV}$, where the controller parameters that have been fine tunes will be burnt into the microcontroller. In order to verify the effectiveness of the proposed controller, the performance behaviour of the PMSM under adaptive PID control is compared with the behaviour of the system under conventional PID control and a passive system.

This paper is structured as follows: the first section contains the introduction and a review of some related works, followed by the mathematical modelling of a PMSM model in the second section. The third section then presents the proposed control structure for the torque tracking control of the PMSM system. The next section provides a performance evaluation of the proposed controller strategy by comparing it with a conventional PID control structure. The final section is the conclusion of this paper.

\section{PERMANENT MAGNET SYNCHRONOUS MOTOR MODELLING}

The PMSM consists of one stator and one rotor, where the structure of the stator winding is constructed in such a way as to produce a sinusoidal flux density in the air gap of the machine. However, the structure of the rotor is similar to a BLDC motor, which contains a permanent magnet motor. Hence the PMSM is modelled on the D-Q frame, such as shown in the equations below:

$$
\begin{gathered}
v_{d}=R_{s} i_{d}+L_{d} d i_{d} / d t-\omega_{e} L_{q} i_{q} \\
v_{q}=R_{s} i_{q}+L_{q} d i_{d} / d t-\omega_{e} L_{d} i_{d}+\omega_{e} \lambda_{p m} \\
p_{E M}=3 / 2\left(v_{d} i_{d}+v_{q} i_{q}\right)
\end{gathered}
$$


where

$\begin{array}{ll}v_{d} & =\mathrm{D} \text {-axis voltage } \\ v_{q} & =\mathrm{Q} \text {-axis voltage } \\ i_{d} & =\mathrm{D} \text {-axis current } \\ i_{q} & =\mathrm{Q} \text {-axis current } \\ R_{s} & =\text { Stator phase resistance } \\ L_{d} & =\mathrm{D} \text {-axis inductance } \\ L_{q} & =\mathrm{Q} \text {-axis inductance } \\ \lambda_{p m} & =\text { Permanent magnet flux linkage } \\ \omega_{e} & =\text { Angular frequency of stator } \\ p_{E M} & =\text { Electric input electric }\end{array}$

The mechanical part of the PMSM can be modelled as follows:

$$
\begin{gathered}
\tau_{e}=J_{s} d \omega_{s} / d t+B_{v} \omega_{s}+\tau_{c}+\tau_{s} \\
p_{s}=\tau_{s} \omega_{s}
\end{gathered}
$$

where

$$
\begin{array}{ll}
J_{s} & =\text { Shaft moment inertia } \\
\tau_{e} & =\text { Electromagnetic torque } \\
\tau_{c} & =\text { Coulomb torque } \\
B_{v} & =\text { Viscous friction coefficient }
\end{array}
$$

The coupling between the electric and mechanical parts can be defined by the following equations:

$$
\begin{gathered}
\tau_{e}=3 / 2(P / 2)\left(\lambda_{p m} i_{q}+\left(L_{d}-L_{q}\right) i_{d} i_{q}\right) \\
\omega_{e}=P / 2 \omega_{s}
\end{gathered}
$$

where $P=$ Number of poles

\section{The $d-q$ Transformation Modelling}

The $d-q$ modelling is related to the transformation of the three phase variables in an $a b c$ coordinate system into an equivalent two-phase system that has an arbitrary speed in the reference frame. This model is used to model and analyse the PMSM. Hence, in the $d-q$ coordinate system the $d$-axis is defined as the direct magnetic axis of the resultant mutual interaction of two orthogonal magnetomotive forces (mmf), while the $q$-axis is the quadrature to the direct axis. In this model the Park transformation is used. The three phase windings $a b c$ are placed in the stator with two windings $d$ and $q$ being placed in the rotor. The calculation of the current and flux are given by Park as

$$
\left[\begin{array}{l}
f_{d} \\
f_{q}
\end{array}\right]=I_{a b c \rightarrow d q}\left[\begin{array}{l}
f_{a} \\
f_{b} \\
f_{c}
\end{array}\right],\left[\begin{array}{l}
f_{\alpha} \\
f_{\beta}
\end{array}\right]={ }_{a b c \rightarrow \alpha \beta}\left[\begin{array}{l}
f_{a} \\
f_{b} \\
f_{c}
\end{array}\right] ;\left[\begin{array}{l}
f_{d} \\
f_{q}
\end{array}\right]={ }_{\alpha \beta \rightarrow d q}\left[\begin{array}{l}
f_{\alpha} \\
f_{\beta}
\end{array}\right]
$$


where

$$
\begin{gathered}
I_{a b c \rightarrow d q}=\frac{2}{3}\left[\begin{array}{ccc}
\cos \theta & \cos (\theta+2 \pi) & \cos (\theta+2 \pi / 3) \\
\sin \theta & \sin (\theta-2 \pi) & \sin (\theta-2 \pi / 3) \\
0.5 & 0.5 & 0.5
\end{array}\right] \\
I_{a b c \rightarrow d q}=\frac{2}{3}\left[\begin{array}{ccc}
1 & -0.5 & -0.5 \\
0 & -\sqrt{3} / 2 & \sqrt{3} / 2 \\
0.5 & 0.5 & 0.5
\end{array}\right] \\
I_{\alpha \beta \rightarrow a b c}=\left[\begin{array}{cc}
\cos \theta & \sin \theta \\
-\sin \theta & \cos \theta
\end{array}\right] \\
I_{d q \rightarrow a b c}=I_{a b c \rightarrow d q}^{-1}, I_{\alpha \beta \rightarrow a b c}=I^{-1}{ }_{a b c \rightarrow \alpha \beta}, I_{d q \rightarrow \alpha \beta}=I^{-1}{ }_{\alpha \beta \rightarrow d q}
\end{gathered}
$$

The $a b c$ variables are obtained from the $d-q$ variable through the inverse of the Park transform.

$$
I_{d q \rightarrow a b c}=\left[\begin{array}{ccc}
\cos \theta & \sin \theta & 1 \\
\cos (\theta-2 \pi / 3) & \sin (\theta-2 \pi / 3) & 1 \\
\cos (\theta+2 \pi / 3) & \sin (\theta+2 \pi / 3) & 1
\end{array}\right]
$$

Where $f_{\text {dref }}$ and $f_{\text {qref }}$ are the current in the $d-q$ frame model, which may be obtained from the 3-phase voltages through the previous equation as:

$$
\begin{gathered}
i_{a}=i_{q} \cos \theta-i_{d} \sin \theta \\
i_{b}=i_{q} \cdot 0.5(1.7321 \sin \theta-\cos \theta)+(\sin \theta+1.7321 \cos \theta) i_{d} \cdot 0.5 \\
i_{c}=-i_{a}-i_{b}
\end{gathered}
$$

\section{Vector Control Model of PMSM}

Vector control of the PMSM is required to undertake the current control loop of a fieldoriented drive of a PMSM. The advantage of the vector control in this system is that vector control can deliver a high performance to the PMSM based on the desired input. Equation (16) shows that when the direct axis (d-axis) is maintained as constant, the generated torque is proportional to the quadrature axis (q-axis) current. For the special case when $i_{d}$ is forced to zero, $\lambda_{d}=\lambda_{a f}$. Then equation (1) becomes:

$$
\begin{gathered}
v_{d}=-\omega_{e} L_{q} i_{q} \\
v_{q}=R_{s} i_{q}+L_{q} \frac{d i_{q}}{d t}-\omega_{e} L_{d} i_{d}+\omega_{e} \lambda_{p m}
\end{gathered}
$$

The expression of torque then will be:

$$
T_{e}=3 / 2(P / 2) \lambda_{a f} i_{q}
$$

where

$$
k_{e}=3 / 2(P / 2) \lambda_{a f}
$$


The magnetic flux linkage of the PMSM is a constant and the torque is directly related to the quadrature axis (q-axis) current.

\section{DESCRIPTION OF THE SIMULATION MODEL}

The model of an electric motor for a series HEV is developed based on the mathematical equations in the previous section using Matlab Simulink Software. In this simulation, the PMSM was controlled using an Adaptive PID controller. The PMSM modelled in the Matlab Simulink Software is illustrated in Figure 1. Thus the subsystem of the electric motor includes a speed controller, DC to DC converter, battery, vector control and inverter. Additionally, the electric motor was run through a battery source. Furthermore, the electric motor has three inputs that can be used in the simulation of the electric motor, namely torque input, speed input and motor enable. The simulation model of the PMSM is shown in Figure 1.

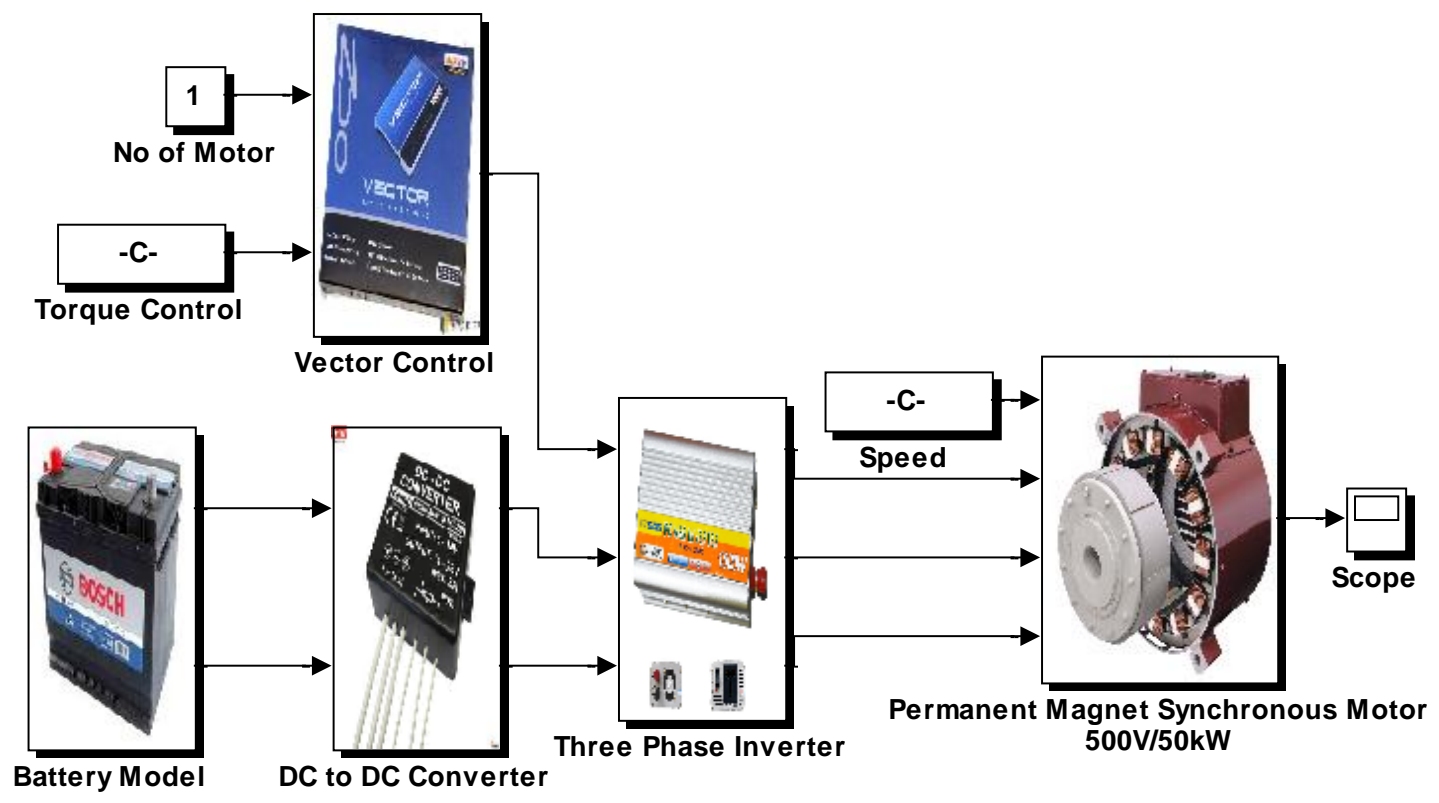

Figure 1. PMSM model in Matlab Simulink Software.

\section{TORQUE TRACKING CONTROL OF PMSM}

The control structure of an active control system for PMSM was classified by an outer loop to control the torque of the motor and speed. The outer loop controller provides the PMSM control, that isolates the PMSM model, speed control, battery, vector control and three phase inverter. The proposed control structure for the permanent magnet motor (PMSM) is illustrated in Figure 2. 


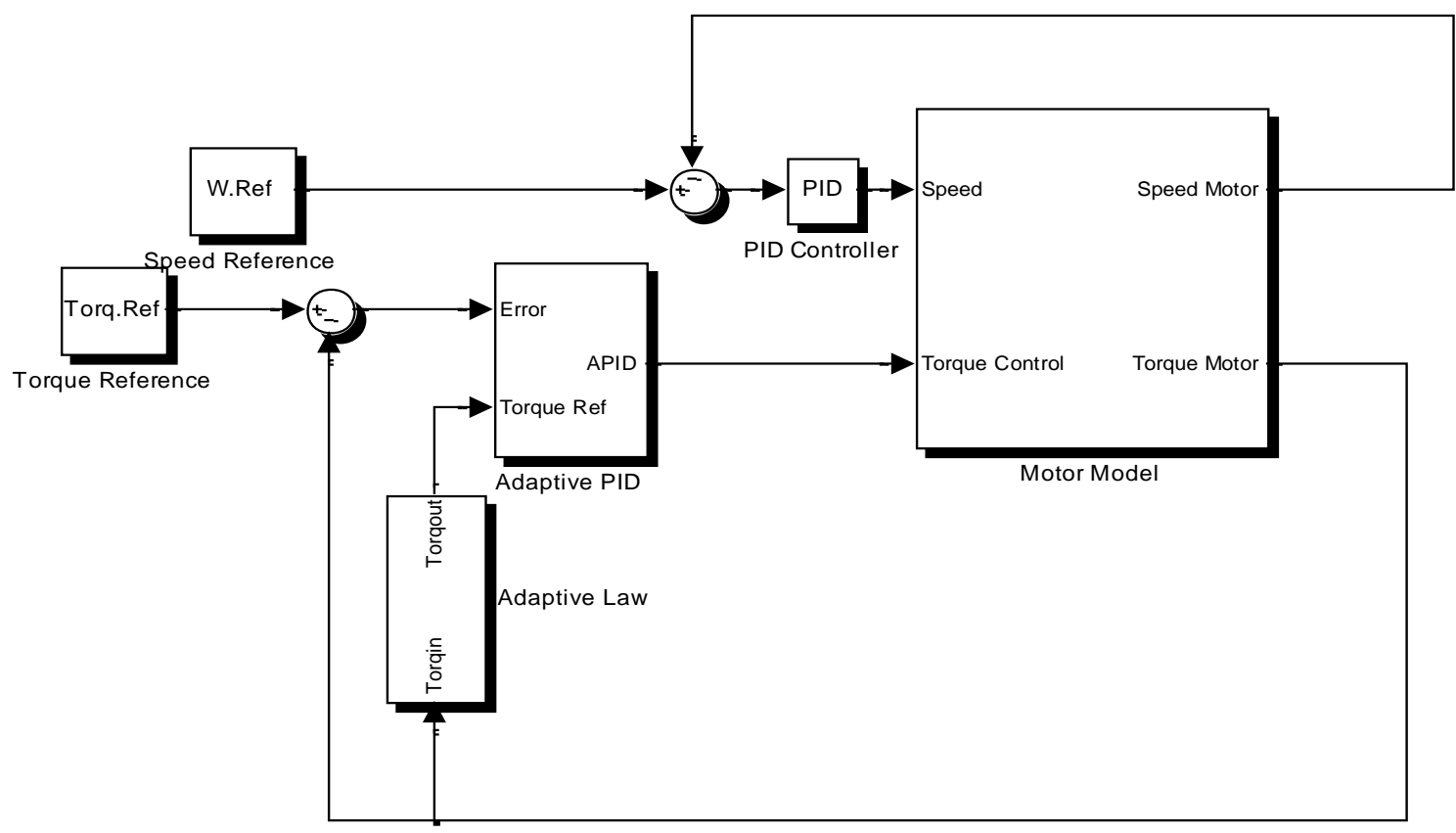

Figure 2. Adaptive PID control structure.

\section{Torque Tracking Control of PMSM}

The controller is used to evaluate the deviation from the required torque with robust and accurate torque performance. From many previous investigations, the PID controller is already proven to be effective in many applications, but is unable to continuously vary with varying conditions. Hence an adaptive PID controller is proposed in this investigation to achieve a better result in terms of the continuity and adaptability of the controller in performing with varying inputs. The control structure of the adaptive PID controller is illustrated in Figure 2. The mathematical equation of the adaptive PID controller can be described by following equations:

$$
\tau_{e}(t)=k_{p}(t) e(t)+k_{i}(t) \int e(t) d t+k_{d}(t) \frac{d}{d t} e(t)
$$

Where, $e(t)=\tau_{\text {ref }}(t)-\tau_{\text {actual }}(t)$ and the proportional gain of $k_{p}(t)$, integral gain, $k_{i}(t)$ and derivative gain, $k_{d}(t)$ are functions of the PMSM torque performance $\tau_{e m}(t)$.

The proportional gain of $k_{p}(t)$ can be expressed mathematically as follows:

$$
k_{p}(t)=-280 \tau_{\text {em }}(t)+43000
$$

The integral gain of $k_{i}(t)$ can be expressed mathematically, equation (22), as a function of the PMSM torque performance as follows:

$$
k_{i}(t)=-190 \tau_{\text {em }}(t)+29000
$$

The derivative of $k_{d}(t)$ can be described mathematically, equation (23), as a function of the PMSM torque performance as follows: 


$$
k_{d}(t)=-120 \tau_{e m}(t)+19000
$$

In this study, the linearisation of the controller gain against motor torque has been made in order to obtain the constant value in equations (20) to (23). The linearisation is done via linearising the plotting data in Microsoft Excel, as discussed in the Appendix. In order to create the linearisation equation, it is necessary to identify the conventional PID controller parameters for all the input conditions via the simulation of a step response, square function response, saw tooth response and sine wave function. The controller parameters obtained from the tests are presented in Table 1.

Table 1. PID controller parameters.

\begin{tabular}{ccccccccc}
\hline Torque & \multicolumn{8}{c}{ Controller Parameter } \\
\cline { 2 - 9 } References & \multicolumn{4}{c}{ Step Response } & \multicolumn{5}{c}{ Sine Wave Response } \\
\cline { 2 - 9 }$(\mathrm{Nm})$ & $K_{p}$ & $K_{i}$ & $K_{d}$ & $\mathrm{~T}_{\mathrm{e}}(\mathrm{Nm})$ & $K_{p}$ & $K_{i}$ & $K_{d}$ & $\mathrm{~T}_{\mathrm{e}}(\mathrm{Nm})$ \\
\hline 150 & 160 & 5 & 2 & 149 & 10000 & 10000 & 9000 & 142 \\
140 & 150 & 10 & 3 & 139 & 10000 & 10000 & 9000 & 135 \\
130 & 135 & 7 & 3 & 129 & 10000 & 8000 & 6000 & 124 \\
120 & 100 & 10 & 2 & 119 & 7800 & 6500 & 4000 & 110 \\
110 & 170 & 5 & 1 & 109 & 12000 & 11000 & 4500 & 102 \\
100 & 150 & 3 & 1 & 99 & 6500 & 6000 & 3500 & 91 \\
\hline
\end{tabular}

\begin{tabular}{ccccccccc}
\hline $\begin{array}{c}\text { Torque } \\
\text { References }\end{array}$ & \multicolumn{3}{c}{ Saw Tooth Response } & \multicolumn{4}{c}{ Square Response } \\
\cline { 2 - 9 }$(\mathrm{Nm})$ & $K_{p}$ & $K_{i}$ & $K_{d}$ & $\mathrm{~T}_{\mathrm{e}}(\mathrm{Nm})$ & $K_{p}$ & $K_{i}$ & $K_{d}$ & $\mathrm{~T}_{\mathrm{e}}(\mathrm{Nm})$ \\
\hline 150 & 250 & 10 & 1 & 136 & 50 & 5 & 1 & 148 \\
140 & 230 & 15 & 5 & 127 & 70 & 5 & 3 & 138 \\
130 & 190 & 13 & 3 & 119 & 45 & 10 & 5 & 128 \\
120 & 185 & 13 & 2 & 110 & 60 & 8 & 2 & 118 \\
110 & 200 & 15 & 3 & 101 & 63 & 7 & 2 & 108 \\
100 & 190 & 12 & 2 & 92.5 & 60 & 10 & 1 & 98 \\
\hline
\end{tabular}

\section{POSITION TRACKING CONTROL OF PMSM USING PID CONTROLLER}

Figure 3 shows the response for a system with the PID controller. The parameters of the PID controller are optimised using the trial and error method, and verified using sensitivity analysis for optimal performance under various conditions. Several test procedures such as the step function, sine wave function, square function and saw tooth function are applied to verify the effectiveness of the control structure. All the input signals are generated from the step function, square function and sine wave function. With appropriate tuning of the PID gains, excellent results are achieved as illustrated in Figure 3. In the graphs, the green/dashed line corresponds to the desired motion of the slider position and the blue/solid line indicates the actual motion achieved by controlling the position torque of the motor. It can be seen that the proposed control structure with the PID controller for producing the desired torque is very encouraging, as shown in the step function response in Figure 3(a). However, the response of the controller in this function is over damped, and it can be said that the system is slow. In terms of the sine wave function [Figure 3(b)], saw tooth function [Figure 3(c)], and 
square function [Figure 3(d)] the controller structure shows its capability in achieving the control design criteria, and presents a good response in tracking the desired torque.

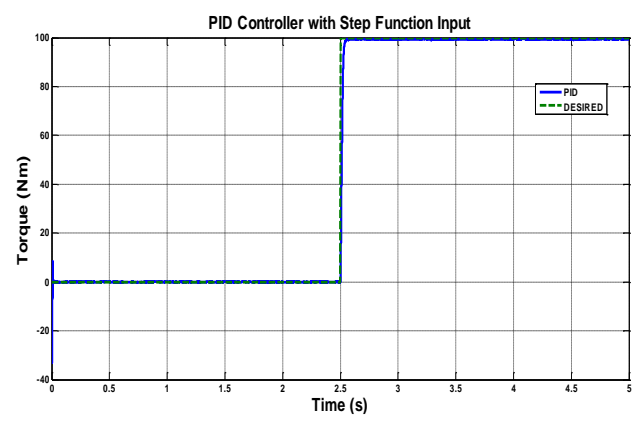

(a). Step Function

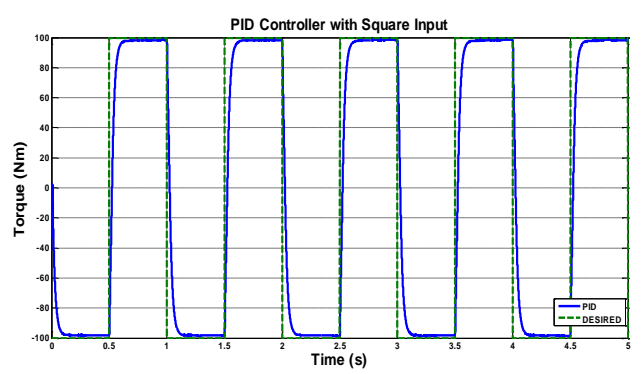

(c). Square Function

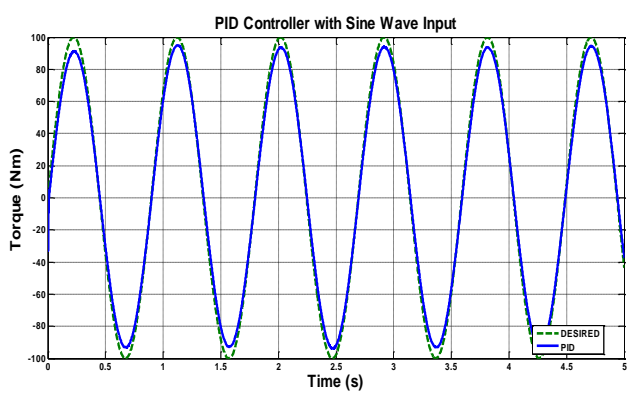

(b). Sine Wave Function

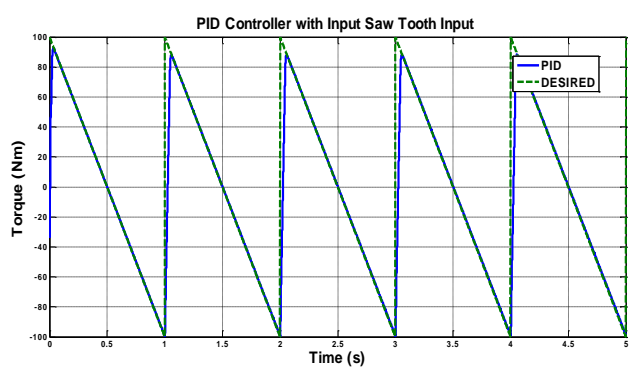

(d). Saw Tooth Function

Figure 3. Response of torque tracking control of PMSM using PID controller.

\section{POSITION TRACKING CONTROL OF PMSM USING ADAPTIVE PID CONTROL}

Since there are limitations to the PID controller in controlling the system, as discussed in section 3.1 and proven in section 4.0, an adaptive PID has been proposed. Figures 4(a) and 4(b) show the performance evaluation of the torque tracking control of the PMSM under the adaptive PID controller. The performance of the controller is examined via comparing the response of the proposed controller with the response of the system under a conventional PID controller and a controller reference. In the figures, the blue/solid lines denote the response of the adaptive PID controller, the red/dashed lines indicate the response of the PID controller, while the green/dotted lines refer to the desired input for the controller. The results show that the APID controller with a moment rejection loop offers a good performance in tracking the system, and also the system is stable and has a good transient response.

Considering Figure 4(a), the step function behaviour of the APID controller indicates a better performance in terms of the rate of the response, transient phase and settling time compared to the conventional PID controller. The results show that the proposed control structure is a reasonably efficient method to achieve identical torque to that desired, since the response of the conventional PID controller is over damped which means that the response of the controller is sluggish. The results of torque tracking control for the sine wave function, saw tooth function and square wave function of the APID controller scheme can be examined in Figures 4(b), (c) and (d). From the observations it can be said that the APID control scheme is able to make the system produce the target torque 
desired, while the conventional PID controller could not achieve that. It can be seen from the response of the PID controller that it cannot achieve the target magnitude desired. In terms of stability, the APID indicates that the controller structure is more stable compared to the PID controller. This can be clearly seen in Figures 4 (a) and (d), where steady state error occurs in the steady state phase.

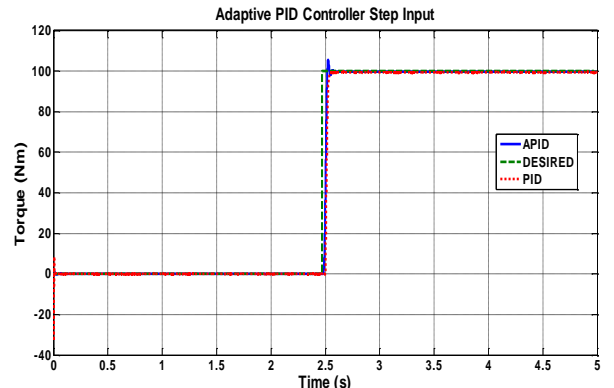

(a). Step Function

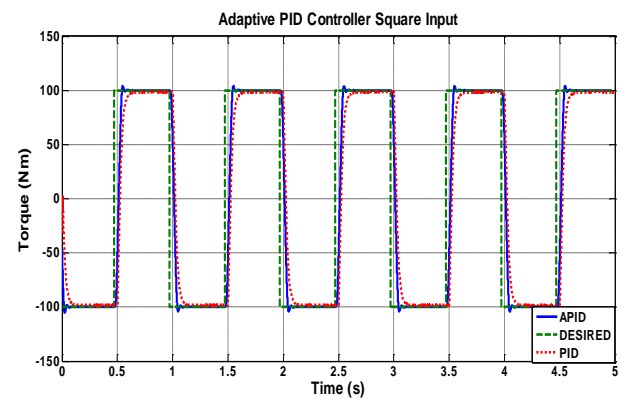

(c). Square Function

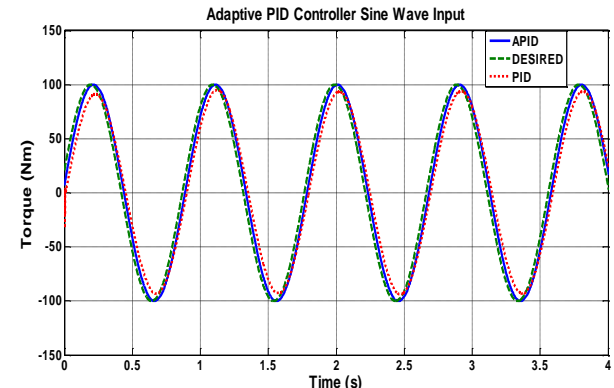

(b). Sine Wave Function

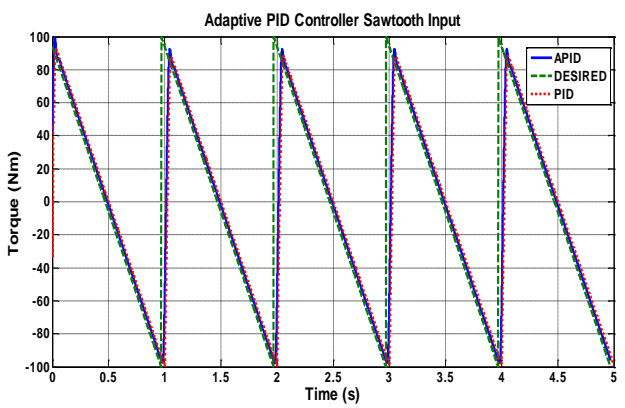

(d). Saw Tooth Function

Figure 4. Response of torque tracking control of PMSM using Adaptive PID controller.

\section{CONCLUSION}

In this study, a PMSM model has been developed in Matlab Simulink Software. The developed model is then used as the electric power train in a HEV simulation. Since the input of the vehicle's dynamics is the drive torque, torque tracking control of the PMSM should first be achieved. In this study, a torque tracking control for the PMSM has been developed using an adaptive proportional-integral-derivative (APID) control scheme. Simulation studies of the torque tracking are presented to demonstrate the effectiveness of using the proposed controller by comparing the responses with the same system using a PID controller and the desired control. Several tests have been performed in order to verify the effectiveness of the proposed controller, namely a sine wave function test, square function test, step function test and saw tooth function test. The simulation results show that the use of the proposed APID control technique proved to be effective in controlling the torque of the PMSM with good accuracy.

\section{ACKNOWLEDGEMENT}

This work is supported by the Universiti Teknikal Malaysia Melaka through a scholarship and financial support under project no. PJP/2012/ACARE/Y00004 entitled 
"Design and Development of Hybrid Electric Vehicle based Series Drive Train Layout", led by Dr. Noreffendy Tamaldin. This financial support is gratefully acknowledged.

\section{REFERENCES}

Ahmad, F., Hudha, K., Imaduddin, F. and Jamaluddin, H. 2010. Modelling, Validation and adaptive pid control with pitch moment rejection of active suspension system for reducing unwanted vehicle motion in longitudinal direction. International Journal of Vehicle Systems Modelling and Testing, 5: 312-346.

Arroyo, E.L.C. 2006. Modeling and simulation of permanent magnet synchronous motor drive system. MSc Thesis, University of Puerto Rico Mayaguez Campus.

Astolfi, A., Karagiannis, D. and Ortega, R. 2008. Nonlinear and Adaptive Control with Applications. Springer.

Bathaee, S.M.T., Gastaj, A.H., Emami, S.R. and Mohammadian, M. 2005. A fuzzybased supervisory robust control for parallel hybrid electric vehicles. IEEE Conference on Vehicle Power and Propulsion, pp. 1-7

Bayindir, C., Kamil, G., Mehmet, A. and Teke, A. 2011. A Comprehensive overview of hybrid electric vehicle: powertrain configurations, powertrain control techniques and electronic control units. Energy Conversion and Management, 52: 13051313.

Belda, K. and Vosmik, D. 2012. Speed control of PMSM drives by generalized predictive algorithms. 38th Annual Conference on IEEE Industrial Electronics Society (IECON 2012), 25-28 Oct., pp. 2012-2017.

Choi, U.D., Kim, K.T., Kim, Y.N., Kwak, S.H., Kim, K.M., Lee, S.D., Jang, S.J. and Becksteard, K. 2006. Development of the power generator for series hybrid electric vehicle. The 1st International Forum on Strategic Technology, pp. 447450.

Cominos, P. and Munro, N. 2002. PID Controllers: recent tuning methods and design to specification. IEE Proceedings on Control Theory and Applications, 149: 46-53.

Desai, C. and Williamson, S.S. 2009. Comparative Study of hybrid electric vehicle control strategies for improved drivetrain efficiency analysis. Electrical Power \& Energy Conference (EPEC), 22-23 Oct., pp. 1-6.

Ehsani, M., Gao, Y. and Emadi, A. 2010. Modern electric, hybrid electric and fuel cell vehicles. In: Rashid, M. H. (ed.) Fundamental, Theory and design, 2nd Edition.

Elmas, C., Ustun, O. and Sayan, H.H. 2008. A Neuro-fuzzy controller for speed control of a permanent magnet synchronous motor drive. Expert Systems with Applications, 34: 657-664.

Garg, D.P. and Kumar, M. 2002. Optimal path planning and torque minimization via genetic algorithm applied to cooperating robotic manipulators. American Society of Mechanical Engineers, Dynamic Systems and Control Division, 70: 71-79.

Grammatico, S., Balluchi, A. and Cosoli, E. 2010. A series-parallel hybrid electric powertrain for industrial vehicles. Vehicle Power and Propulsion Conference (VPPC), 1-3 Sept., pp. 1-6.

Guo, Y. and Long, H. 2011. Self organizing fuzzy sliding mode controller for the position control of a permanent magnet synchronous motor drive. Ain Shams Engineering Journal, 2: 109-118.

Huang, H.P., Roan, M.L. and Jeng, J.C. 2002. On-line adaptive tuning for PID controllers. IEE Proceedings on Control Theory and Applications, 149: 60-67. 
Karabacak, M. and Eskikurt, H.I. 2011. Speed and Current regulation of a permanent magnet synchronous motor via nonlinear and adaptive backstepping control. Mathematical and Computer Modelling, 53: 2015-2030.

Kristiansson, B. and Lennartson, B. 2002. Robust and optimal tuning of PI and PID controllers. IEE Proceedings on Control Theory and Applications, 149: 17-25.

Li, C.Y., Jing, W.X. and Gao, C.S. 2009. Adaptive backstepping-based flight control system using integral filters. Aerospace Science and Technology, 13: 105-113.

Lin, F.J., Lin, Y.S. and Chiu, S.L. 1998. Slider-crank mechanism control using adaptive computed torque technique. IEE Proceedings on Control Theory and Applications, 145: 364-376.

Melin, P. and Castillo, O. 2005. Intelligent control of a stepping motor drive using an adaptive neuro-fuzzy inference system. Information Sciences, 170: 133-151.

Momoh, O.D. and Omoigui, M.O. 2009. An overview of hybrid electric vehicle technology. Vehicle Power and Propulsion Conference, pp. 1286-1292.

Montazeri-Gh, M., Poursamad, A. and Ghalichi, B. 2006. Application of genetic algorithm for optimization of control strategy in parallel hybrid electric vehicles. Journal of the Franklin Institute, 343: 420-435.

Moustakidis, S.P., Rovithakis, G.A. and Theocharis, J.B. 2008. An adaptive neurofuzzy tracking control for multi-input nonlinear dynamic systems. Automatica, 44: 1418-1425.

Pennestrì, E., Mariti, L., Valentini, P.P. and Mucino, V.H. 2012. Efficiency evaluation of gearboxes for parallel hybrid vehicles: theory and applications. Mechanism and Machine Theory, 49: 157-176.

Qi, L. and Shi, H. 2013. Adaptive position tracking control of permanent magnet synchronous motor based on RBF fast terminal sliding mode control. Neurocomputing, 115: 23-30.

Salmasi, F.R. 2007. Control strategies for hybrid electric vehicles: evolution, classification, comparison, and future trends. IEEE Transactions on Vehicular Technology, 56: 2393-2404.

Trabelsi, R., Khedher, A., Mimouni, M.F. and M'sahli, F. 2012. Backstepping control for an induction motor using an adaptive sliding rotor-flux observer. Electric Power Systems Research, 93: 1-15.

Trigui, R., Desbois-Renaudin, M., Jeanneret, B. and Badin, F. 2004. Global forwardbackward approach for a systematic analysis and implementation of hybrid vehicle management laws. Application to a two clutches parallel hybrid powertrain. European ELE-DRIVE Transportation Conference, pp. 422-427.

Yimin, G. and Ehsani, M. 2006. A torque and speed coupling hybrid drivetrainarchitecture, control, and simulation. IEEE Transactions on Power Electronics, 21: 741-748.

Yuan, Z., Yaobin, C., Guangyu, T., Hao, W. and Quanshi, C. 2004. A four-step method to design an energy management strategy for hybrid vehicles. American Control Conference, 1: 156-161.

Zhu, Y., Chen, Y. and Chen, Q. 2002. Analysis and design of an optimal energy management and control system for hybrid electric vehicles. In: Proceedings of the 19th International Electric Vehicle Symposium (EVS19), pp. 13-24. 


\section{APPENDIXES}

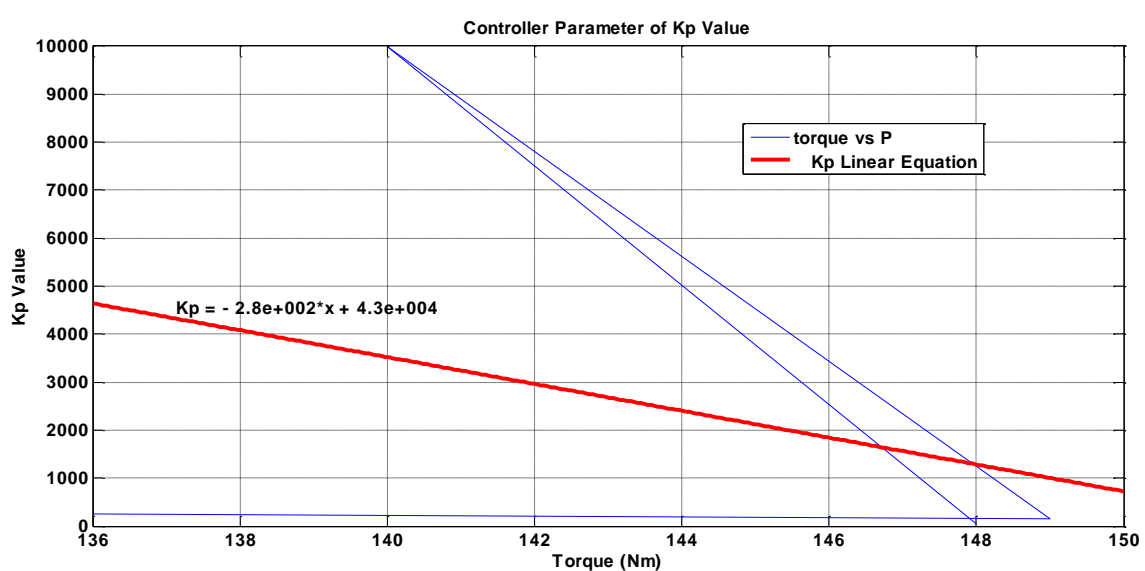

(a) Kp Value

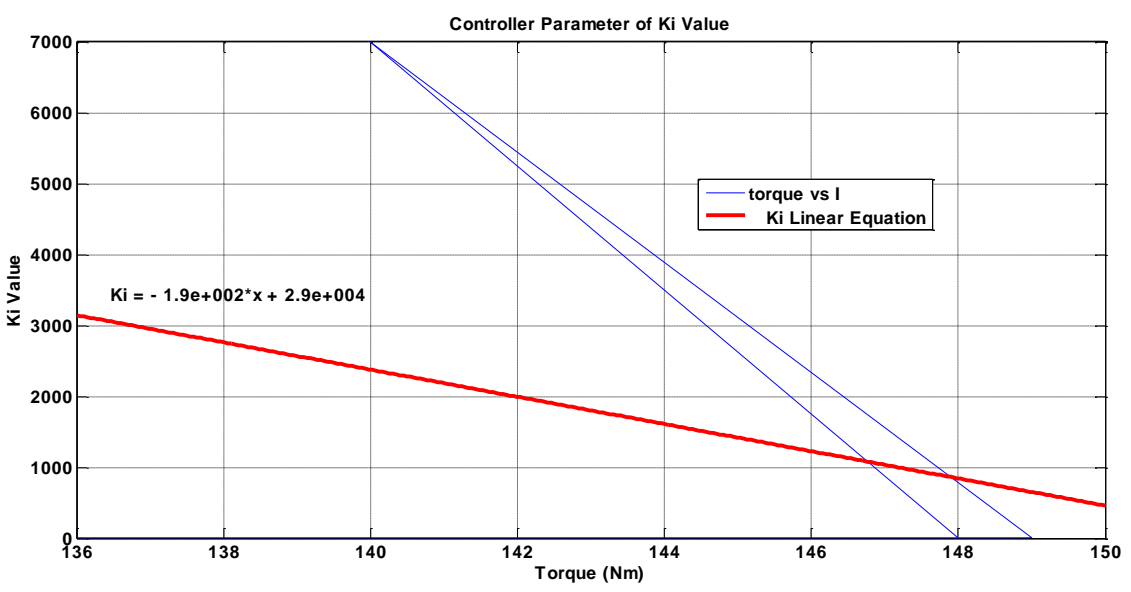

(b) Ki Value

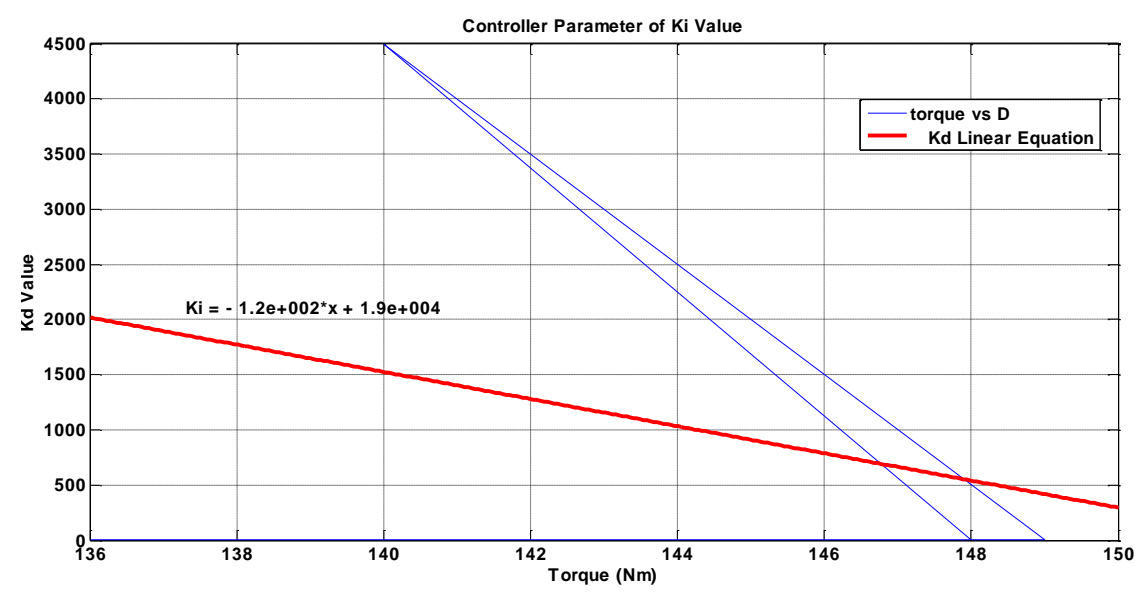

(c) Kd Value 